\title{
Vaginal and Bladder Rupture without Uterine Rupture in Unscarred Uterus
}

\author{
${ }^{1}$ Ruchika Garg, ${ }^{2}$ Saroj Singh, ${ }^{3}$ Abhilasha Yadav, ${ }^{4}$ Arun Kumar, ${ }^{5}$ Sangeeta Sahu, ${ }^{6}$ Rachana Agarwal
}

\begin{abstract}
Introduction: Risk of uterine rupture in obstructed labor in grand multipara in developing countries is well documented; however, rupture of vagina involving bladder is uncommon. Below is described a rare case of 30 -year-old grand multipara who suffered vaginal rupture associated with bladder rupture rather than uterine rupture during second stage of labor. This case is an important reminder to obstetricians that vaginal rupture can also occur in unscarred uterus without uterine involvement.
\end{abstract}

Keywords: Bladder rupture, Grand multipara, Obstructed labor, Vaginal rupture.

How to cite this article: Garg R, Singh S, Yadav A, Kumar A, Sahu S, Agarwal R. Vaginal and Bladder Rupture without Uterine Rupture in Unscarred Uterus. J South Asian Feder Obst Gynae 2017;9(3):269-270.

\section{Source of support: Nil}

Conflict of interest: None

Date of received: 5 June 2017

Date of acceptance: 23 June 2017

Date of publication: August 2017

\section{INTRODUCTION}

Risk of uterine rupture during labor in grand multipara is well documented. Below is described a rare case of a patient who suffered a vaginal rather than uterine rupture during second stage of spontaneous labor. Very few cases have been described in literature till now.

\section{CASE REPORT}

A 30-year-old grand multiparous women gravida five, para four with term pregnancy presented to labor room in second stage of labor. She had four spontaneous full-term normal vaginal home deliveries. She had no past history

\footnotetext{
${ }^{1,4,6}$ Assistant Professor, ${ }^{2}$ Professor, ${ }^{3,5}$ Lecturer

1-3,5,6 Department of Obstetrics and Gynecology, Sarojini Naidu Medical College, Agra, Uttar Pradesh, India

${ }^{4}$ Department of Surgery, Sarojini Naidu Medical College, Agra Uttar Pradesh, India

Corresponding Author: Ruchika Garg, Assistant Professor Department of Obstetrics and Gynecology, Sarojini Naidu Medical College, Agra, Uttar Pradesh, India, Phone: +919720004485 e-mail: ruchikagargagra@gmail.com
}

of gynecological or obstetrical surgery or spontaneous or induced abortion. She was pale, blood pressure-96/60 mm $\mathrm{Hg}$, pulse rate $-124 /$ minute, respiratory rate $42 /$ minute. On abdominal examination, uterine contour was irregular and fetal parts were felt with ease, fetal heart sound was absent. On per vaginal examination bleeding per vaginum was present, os was completely dilated, and presenting part could not be reached. On catheterization, frank blood was present in Foley catheter.

After securing IV lines and sending the blood specimen for grouping and cross matching, patient was immediately shifted to operation theater and surgery call sent because of possibility of associated urinary tract injury.

Patient was given general anesthesia and abdomen opened by midline incision. But after opening parietal peritoneum, visceral peritoneum could not be identified, no hemoperitonium was present, and fetus was visible through thin and stretched anterior wall of bladder. This thin and stretched anterior bladder gave way and a dead fetus was delivered through bladder.

At this point of time, anterior wall of bladder was found torn with trigone involved and large rent was found in posterior bladder wall. Uterus and cervix were intact and avulsion occurred at anterior vaginal fornix at the level of cervix involving the posterior bladder wall. Opinion was sought from senior obstetrician and with consensus that the degree of damage and bleeding warranted hysterectomy. This was performed with assistance of surgeon. Posterior bladder wall was repaired and bilateral ureteric drain was placed, trigone of bladder along with anterior bladder wall was repaired, and suprapubic drain was inserted in bladder. After placing abdominal drain, abdomen was closed in layers.

Approximate total time taken during the procedure was 4 hours, total blood loss during the procedure was about $1.5 \mathrm{~L}$, and 2 units of packed red blood cells, 2 units of fresh frozen plasma and $4 \mathrm{~L}$ of crystalloids transfused during operation.

Postoperatively, patient was transferred to intensive care unit where patient was intubated and ventilated till next morning. During this period, she recovered well. On 14th day, ureteric stents were removed and patient was discharged. After 1 week, patient came to outpatient department (OPD) where suprapubic drain was also removed. Patient was called to attend OPD at sixth postoperative week and Foley's catheter removed. 


\section{DISCUSSION}

Vaginal trauma sustained during first stage of labor is common worldwide, especially if there is no or poor intrapartum care and manifests either as traumatic postpartum hemorrhage or as obstetric fistulas secondary to obstructed labor. But case of vaginal rupture is rare and even rarer in unscarred uterus and absence of vaginal atresia. Young et $\mathrm{al}^{1}$ reported a case of large tear in posterior vaginal wall while in spontaneous labor at 28 weeks. In this case, rupture vagina was attributed to vaginal atresia. Spaulding ${ }^{2}$ reported a case in which patient was given trial of labor at 39 weeks with oxytocin drip and suffered uterine and vaginal rupture. Two infants were delivered through maternal bladder one after uterine dehiscence and other after vaginal rupture. In this case, rupture was attributed to oxytocin drip. Schultz and $\mathrm{Nanda}^{3}$ reported a case where vaginal injury was diagnosed at the time of cesarean section while trying to obtain hemostasis. Persistent bleeding was present from an extension of left uterine incision, which reflected the avulsion of anterior vaginal wall. None of these were diagnosed prior to laparotomy. Allen et $\mathrm{al}^{4}$ reported a case of a patient presenting with obstructed labor. Examination revealed a crowning fetal head, no fetal heart tones, and purulent vaginal discharge. Postpartum, the patient experienced irritative voiding symptoms, vaginal stenosis, and cystoscopic evidence of injury to the bladder base.

\section{CONCLUSION}

While cases, such as one discussed above are exceptionally rare, it is an important reminder to obstetricians that rupture of vagina and bladder in the absence of uterine rupture even in unscarred uterus and even in absence of vaginal stenosis do occur and must be considered in clinical situations where another explanation is not apparent.

\section{REFERENCES}

1. Young B, Takoudes T, Lim KH, Rana S. Rupture of the posterior cul-de-sac during spontaneous labour. Obstet Gynecol 2010 Feb;115(2 Pt 2):414-417.

2. Spaulding LB. Delivery through the maternal bladder during trial of labour. Obstet Gynecol 1992 Sep;80(3 Pt 2):512-514.

3. Schultz MJ, Nanda T. Spontaneous rupture of anterior vaginal wall during first stage of labour. Case Rep Obstet Gynecol 2012;2012:2. Available from: http:dx.org/10.1155/ 2012/786753.

4. Allen AM, Lakin T, Shobeiri SA, Nihirra M. Transmural vaginal to bladder injury from an obstructed labour pattern. Obstet Gynaecol 2011 Feb;117(2 Pt 2):468-470. 